\title{
El calamar de los tentáculos de oro. Un análisis de la pesca china en Perú (2000-2020)
}

\author{
The squid of the golden tentacles. An analysis of Chinese fishing in Peru \\ (2000-2020)
}

\section{A lula dos tentáculos dourados. Uma análise da pesca chinesa no Peru (2000-2020)}

Federico Ortega ${ }^{a}$, Darío Saavedra $^{b}$ y Federico Esquiroz ${ }^{c}$

Instituto de Investigaciones en Humanidades y Ciencias Sociales. Facultad de Humanidades y Ciencias de la Educación. Universidad Nacional de La Plata. Argentina

${ }^{a}$ Autor corresponsal: federicortega74@gmail.com - https://orcid.org/0000-0003-2654-9352

b saav1974@gmail.com - https://orcid.org/0000-0002-1539-217X

c federicoesquiroz@abc.gob.ar - https://orcid.org/0000-0003-2686-300X

\begin{abstract}
RESUMEN
Las flotas de pesqueros de capitales chinos extraen recursos a escala global en los océanos del mundo para abastecer a su creciente mercado interno de productos marítimos, como el calamar gigante Dosydicus gigas. Al igual que el gigante asiático, otras potencias en el rubro llevan a cabo una explotación de tinte extractivista sobre las aguas internacionales adyacentes a las jurisdicciones de países ribereños como el Perú y en todos los mares del mundo, alimentados por generosos subsidios estatales. Esto no evita que, en ocasiones, las flotas incurran en prácticas como la pesca ilegal, no declarada, no reglamentada y la explotación de trabajadores, con el peligro latente de la sobreexplotación de los recursos marítimos, y los perjuicios tanto para la biodiversidad como para al ecosistema que esto conlleva. El proceso se complementa con la inserción en el circuito legal de la pesca, en este caso, en el Perú, mediante fusiones y adquisiciones de varias compañías del rubro.
\end{abstract}

En el contexto de estas prácticas extractivistas, y en el marco de una guerra mundial, híbrida y fragmentada, se desarrolla un conflicto por el control del Pacífico Sur entre China y los Estados Unidos, en la cual el Gobierno norteamericano encabeza acciones y críticas contra las políticas chinas, usando el discurso de varias Organizaciones No Gubernamentales. Las acciones y posturas de ambos bandos tienen implicancias geoestratégicas, que tuvieron un pico con la aparición de las flotas chinas en el Pacífico Sur durante los meses de agosto a octubre del 2020.

\section{ABSTRACT}

The Chinese capital fishing fleets extract resources on a global scale in the oceans of the world in order to supply their growing domestic market for marine products, such as the giant squid Dosydicus gigas. Like the Asian giant, other powers in the field carry out extractive exploitation in international waters adjacent to the jurisdictions of riparian countries such as Peru and in all the seas of the world, fed by generous subsidies. This does not prevent fleets from sometimes engaging in practices such as illegal, unreported, unregulated fishing and the exploitation of workers, within the latent danger of overexploitation of maritime resources, with the damage to biodiversity and the ecosystem that 
this entails. The process is complemented by insertion into the legal fishing circuit, in this case, in Peru, through mergers and acquisitions of various companies in the field.

In the context of these extractivist practices, and in the framework of a hybrid and fragmented world war, a conflict develops between China and the United States for control of the South Pacific, in which the North American government leads actions and criticisms against the Chinese policies, using the speech of various Non-Governmental Organizations. The actions and positions of both sides have geostrategic implications, which peaked with the appearance of the Chinese fleets in the South Pacific during the months of August to October 2020.

\title{
RESUMO
}

As frotas pesqueiras da capital chinesa extraem recursos em escala mundial nos oceanos do mundo, para abastecer seu crescente mercado interno de produtos marinhos, como a lula gigante Dosydicus gigas. Como o gigante asiático, outras potencias no campo realizam uma exploração extrativista em águas internacionais adjacentes às jurisdições de países ribeirinhos como o Peru e em todos os mares do mundo, alimentados por generosos subsídios estatais. Isso não impede que as frotas, por vezes, se envolvam em práticas como a pesca ilegal, não declarada, não regulamentada e a explotação de trabalhadores, com o perigo latente de sobre-exploração dos recursos marítimos e danos tanto à biodiversidade quanto à o ecossistema que isso acarreta. O processo se complementa com a inserção no circuito de pesca legal, neste caso, no Peru, por meio de fusões e aquisições de várias empresas do ramo.

\begin{abstract}
No contexto dessas práticas extrativistas, e no marco de uma guerra mundial híbrida e fragmentada, desenvolvesse um conflito entre a China e os Estados Unidos pelo controle do Pacífico Sul, no qual o governo norte-americano conduz ações e criticas contra Políticas chinesas, usando o discurso de várias organizações não governamentais. As ações e posições de ambos lados tem implicações geoestratégicas, que culminaram com o aparecimento das frotas chinesas no Pacífico Sul durante os meses de agosto a outubro de 2020.
\end{abstract}

PALABRAS CLAVE: Pesca; calamar; Pacífico Sur; China; Estados Unidos.

KEYWORDS: Fishing; squid; Southern Pacific; China; United States.

PALAVRAS CHAVES: Pesca; lula; Pacífico Sul; China; Estados Unidos.

\section{Introducción}

Desde la década del 2000, China protagonizó un proceso de mayor inserción en la economía de América Latina, para asegurar el suministro de materias primas y abastecer tanto su creciente producción como su demanda interna. Svampa (2013) se refiere a esta nueva etapa como el Consenso de los Commodities, en tanto los mismos revisten el ingreso de América Latina en un nuevo orden económico y políticoideológico, sostenido por el boom de los precios internacionales de las materias primas y los bienes de consumo demandados cada vez más por los países centrales y las potencias emergentes, como el caso chino (Svampa, 2013, s/p).

Las prácticas pesqueras chinas, tanto en el caso peruano como en otros países de América Latina previamente analizados (Ortega, Saavedra, Esquiroz, 2019, 2019a) se pueden englobar dentro del concepto de extractivismo. Gudynas (2015) concibe al término como una forma particular de apropiación y extracción de recursos naturales, de parte de países o empresas, en grandes volúmenes o intensidad y su exportación a los mercados globales, con una escasa o nula generación de valor agregado o industrialización en los países de extracción. Para este autor, los extractivismos se basan en la vinculación global entre el sitio de explotación y, vía exportación, el mercado receptor demandante, sin soslayar la existencia de gobiernos que consientan, aprueben y fomenten estas prácticas, que reciben un pequeño porcentaje en forma de regalías. Esta conceptualización responde a las características de las empresas pesqueras de capitales chinos en el Perú. La situación de las adyacencias a la Zona Económica Exclusiva peruana representa un caso particular de extractivismo que, si bien es realizado por fuera de las jurisdicciones estatales, se explotan recursos naturales para el consumo interno o la exportación con procesamiento previo. Se 
abordará el caso del calamar Dosydicus gigas o pota, uno de los principales productos explotados por las flotas extranjeras, de peso clave en las exportaciones pesqueras peruanas y con escaso agregado de valor para su congelamiento o procesamiento para conservas. La explotación del calamar gigante en aguas adyacentes a la jurisdicción del Perú puede representar un peligro para la sostenibilidad de la especie, si la pesca es indiscriminada y si se extraen ejemplares juveniles o inmaduros.

Se tomará como principio rector del artículo a la concepción de Bouvet y Carut (2019), que consideran al mar como bien común, con políticas territoriales planteadas según las necesidades de los gustos alimentarios y de la economía, las cuales se basan en una serie de alambrados invisibles, patentes en posibilidades legales de explotación y dominio territorial, junto a decisiones e intervenciones de organizaciones supranacionales y las políticas propias de cada lugar (Bouvet y Carut, 2019: 3). Para Bouvet (2018), estos alambrados se habrían consolidado desde el Convenio de Montego Bay, en 1982, el cual fijó el derecho de los Estados ribereños sobre sus recursos marítimos hasta 200 millas náuticas después de sus respectivas costas (Bouvet, 2018: 199).

En el caso de las aguas internacionales, estas funcionan como una especie de territorios comunales de facto, sin jurisdicción directa de Estado alguno, pero con legislaciones y controles que dependen de los Organismos Reguladores de Ordenación Pesquera, basados mayoritariamente en los consensos y el diálogo entre los Estados ribereños e interesados en una determinada región marítima del mundo.

En el caso pesquero, Cóccaro et al., (2002) considera que la pesca pasó de ser una actividad de recolección hasta antes de la década de los setenta a ser una actividad de extracción minera, al formar parte de "un espacio diferenciado producto de las peculiaridades que imprime el contacto de dominios diferentes, involucrando las franjas contiguas de tierra y agua", (Cóccaro et al., 2002: s/p). Siendo continente y contenido de una realidad relacional entre ambas variables. En este marco, se puede considerar al extractivismo pesquero como un concepto fundamental, donde se ve esta situación de contacto y diálogo entre la tierra y el océano.

La extracción y apropiación de recursos naturales en zonas fuera del control inmediato de los Estados nacionales que afectan de forma inmediata a sus economías es un aspecto fundamental de esta actividad económica, sumado a la intromisión ocasional de pesqueros en aguas jurisdiccionales de los países y la competencia con flotas legales por los mismos recursos marítimos. Las flotas que suelen actuar fuera del marco legal de los Estados ribereños como el Perú, son mayoritariamente de capitales de China, Taiwán, Corea del Sur, España, Rusia, entre otros. La rentabilidad de estas flotas reside en la menor cantidad de costos fijos, no sólo por los subsidios a los combustibles, sino por la ausencia de permisos o licencias pesqueras e impuestos a la exportación, y por la mayor posibilidad de aprovechamiento de distintos ciclos madurativos de las especies en aguas internacionales.

Una parte de estas prácticas se pueden englobar dentro del concepto de Pesca Ilegal, No Declarada y No Reglamentada (pesca INDNR). La Organización de las Naciones Unidas para la Alimentación y la Agricultura (FAO) define a la pesca ilegal como la "realizada por buques nacionales o extranjeros en aguas bajo la jurisdicción de un Estado, sin el permiso de este o contraviniendo su legislación (...), las medidas de conservación y ordenación adoptadas por (organizaciones regionales de ordenación pesquera competentes)". La pesca no declarada o declarada de modo inexacto a la autoridad nacional competente $\mathrm{u}$ organización regional de ordenación pesquera y la pesca no regimentada, se define como aquella "realizada en la zona de aplicación de una organización regional de ordenación pesquera competente por buques sin nacionalidad, o que enarbolan el pabellón de un Estado que no es parte de esa organización, o por una entidad pesquera, de una manera que no está en consonancia 
con las medidas de conservación y ordenación de dicha organización, o que las contraviene" (FAO, 2020a, s/p).

Se considerará, como hipótesis de trabajo, que las prácticas pesqueras de los capitales sobre todo chinos en los mares bajo jurisdicción peruana y sus adyacencias forman parte de una estrategia extractivista de escala global para el abastecimiento barato y verticalmente integrado de calamar gigante. En la jurisdicción del Perú, esto conllevó un proceso de adquisición de firmas peruanas, el uso de sus licencias pesqueras e infraestructura preexistente, con cuantiosas inversiones en este ámbito.

A su vez, los capitales chinos mantienen un sistema de pesca del calamar en aguas fuera del control jurisdiccional peruano, en varias ocasiones reñido con las prácticas legales internacionalmente acordadas, como los Acuerdos del Estado Rector del Puerto. Algunas acciones de estas flotas son pasibles de ser clasificadas como de pesca ilegal, no declarada y no reglamentada, como la pesca en aguas internacionales, con irregularidades en las declaraciones de capturas, la sobreexplotación de los recursos y las transferencias en altamar.

Esta situación tiene como opositor a una miríada de Organizaciones No Gubernamentales, muchas de las cuales son de origen ofinanciamiento estadounidense e incluso conforman parte de lo que Merino $(2018,2019)$ denomina como globalistas, de los cuales el Gobierno estadounidense, a pesar de que el autor los considera como americanistas-nacionalistas y reñidos con esta primera corriente ideológica, toma muchos de sus postulados a favor, como herramienta para agudizar las tensiones y perjudicar los intereses chinos en el Pacífico sur. Esto se puede constatar en las acciones de las flotas mayoritariamente chinas en adyacencias de las aguas ecuatorianas y peruanas durante los meses de agosto a octubre del 2020.

Actualmente (octubre del 2020), el mundo está en el marco de una guerra mundial, híbrida y fragmentada, en el cual se agudizan las tensiones entre las fuerzas unipolares, como Estados Unidos, el Reino Unido y la OTAN y los núcleos de poder internos de cada país, contra fuerzas que pretenden un orden multipolar no hegemonizado ni diseñado por lo que se conoce como Occidente, es decir, las fuerzas unipolares. Estas tensiones, según Merino y Rang se manifiestan en distintos escenarios del planeta, con tácticas como guerras de monedas, comercial, financiera, ecológica, psicológica, de contrabando, mediática, de drogas, en redes, tecnológica, de fabricación, de recursos, de ayuda económica, cultural y en leyes internacionales (Merino y Rang, 2016: 62-63).

Los océanos se pueden considerar como un espacio de disputa geopolítica y geoestratégica entre las distintas potencias y los países ribereños, que intentan asegurar el control tanto de los recursos ictícolas y minerales en sus jurisdicciones, como de zonas vitales para la comunicación entre los distintos países y regiones, al cubrir el 70\% de la superficie del planeta. Si bien la extensión de los mismos hace prácticamente imposible su dominio absoluto como en el caso de los espacios terrestres, distintos exponentes de la geopolítica puntualizaron sobre la importancia del control de zonas marítimas estratégicas y de la posesión de flotas militares para el ejercicio del dominio sobre los mares aunque, en el contexto de una creciente importancia de los recursos alimenticios a escala mundial, las flotas pesqueras cobraron una relevancia inusitada, de la mano de diversos adelantos tecnológicos y logísticos.

En este artículo se busca profundizar sobre las lógicas de ambos bandos y los recursos tácticos, políticos, económicos y discursivos utilizados para lograr sus objetivos económicos y geoestratégicos, para lo cual se realizará un análisis empírico de fuentes de diversa procedencia, como documentación oficial de los Gobiernos del Perú, de China, de los Estados Unidos, además de reportes de Organizaciones No Gubernamentales, think tanks y escritos académicos, tanto de la temática como de cuestiones económicas, políticas y geoestratégicas. 
El período de análisis abarcará desde el año 2000, de forma de cubrir la inserción progresiva de China, un actor clave en el tema que se analiza, y se tomará como espacio a analizar no solo el Mar de Grau, sino la región denominada por la FAO como Área 87, que abarca el Pacífico Sudoriental, desde el norte de Colombia (paralelo $7^{\circ} 12^{\prime} 39^{\prime \prime}$ Norte) al meridiano $120^{\circ}$ Oeste y desde allí hasta al sur de Chile, al paralelo $60^{\circ}$ Sur y hasta el meridiano $67^{\circ} 16^{\circ}$ Oeste (Organización de las Naciones Unidas para la Alimentación y la Agricultura, s/f), con especial énfasis en las adyacencias de la Zona Económica Exclusiva del Perú. Debido a que el objetivo prioritario será el análisis de la estructura económica pesquera peruana, su relación con las cadenas globales de valor sobre todo chinas y la situación en el marco de la guerra mundial, híbrida y fragmentada, no se profundizará en los aspectos políticos peruanos, lo cual quedará pendiente para otro artículo.

\section{La pesca del calamar gigante (pota). Marco legal, prácticas establecidas y acciones frente a las flotas ilegales.}

El Dosydicus gigas es una especie marítima migratoria de hasta 120 centímetros de longitud de manto y una expectativa de vida de un año, con una disponibilidad variable debido a las variaciones climáticas permanentes de la región. Su población aumenta con los eventos fríos moderados y la mayor disponibilidad de zooplancton (Paredes, 2012). El hábitat de la especie se ubica en la vertiente continental, las áreas de surgencia, las aguas costeras y oceánicas del Pacífico oriental, en la confluencia de aguas superficiales cálidas y costeras frías, entre las 10 y 500 millas náuticas de la costa, con distribuciones más dispersas en los meses de verano (Csirke et al., 2018). La existencia de la corriente de Humboldt en costas peruanas que, según un estudio de 1947 retomado por Morzone (1982), tendría un límite biológico de 200 millas, es la que genera las riquezas del mar peruano, debido a la existencia de corrientes de agua fría que se potenciarían por la provisión de nitratos y fosfatos a causa de la erosión de los Andes (Morzone, 1982: 211).

Esta especie es muy voraz, con una alimentación basada en zooplancton, peces, otros cefalópodos e incluso el canibalismo. El desove principal ocurre entre los meses de octubre y enero, con otro pico entre julio y agosto, aunque la actividad reproductiva se mantiene durante todo el año (Csirke et al., 2018).

La actividad extractiva del calamar gigante propiamente dicha se inició para 1991, con la participación de embarcaciones de Corea del Sur y Japón, que utilizaban luces de atracción para atraer tanto el zooplancton como peces, especies pelágicas y meso pelágicas de las que se alimenta la pota, capturándolo en poteras. Este sistema, denominado jigger, es utilizado en embarcaciones de más de doscientas toneladas de capacidad. Las embarcaciones pesqueras artesanales poseen una capacidad de 10 toneladas de almacenamiento, utilizando métodos manuales y cortineras. En ese primer año, la flota artesanal capturó 21 mil toneladas de calamares, llegando a 43 mil en 1994, en comparación con las 61 mil y 170 mil toneladas capturadas por los buques extranjeros entre 1991 y 1994, usualmente dentro de las 150 millas marítimas de distancia de la costa (Csirke et al., 2018).

La temporada alta de pota se ubica entre marzo y junio, con menor porcentaje de capturas entre enero, febrero, julio y octubre-diciembre. El $81 \%$ de los desembarcos se utilizan en la industria del congelado y el $15.4 \%$ para su procesamiento en fresco y exportaciones de un total de 158,2 millones de dólares en 2010 y 231 millones de dólares en 2011, con España, China, Corea del Sur y Japón como principales destinos (Paredes, 2012).

La mayoría de las exportaciones pesqueras peruanas se orientan, en primer lugar, a China y a España en segundo lugar desde 2019, seguidos por Estados Unidos (segundo lugar hasta el 2018), Japón y Corea del Sur, entre otros. En la Tabla 1 se 
pueden evidenciar las proporciones de las exportaciones pesqueras y la variabilidad del recurso a causa de condiciones climáticas como el fenómeno de El Niño en 2016.

Tabla 1. Exportaciones pesqueras peruanas de calamares y exportaciones destinadas a China (datos en millones de dólares).

\begin{tabular}{cccccc}
\hline Año & $\begin{array}{c}\text { Exportaciones } \\
\text { pesqueras a } \\
\text { China (millones } \\
\text { de dólares). }\end{array}$ & $\begin{array}{c}\text { Exportaciones de } \\
\text { calamar y pota } \\
\text { congelados a } \\
\text { China (millones de } \\
\text { dólares). }\end{array}$ & $\begin{array}{c}\text { Porcentaje de } \\
\text { exportaciones de } \\
\text { calamares por sobre el } \\
\text { total de exportaciones } \\
\text { a China. }\end{array}$ & $\begin{array}{c}\text { Exportaciones al } \\
\text { segundo país receptor } \\
\text { de productos pesqueros } \\
\text { peruanos en millones de } \\
\text { dólares (País) }\end{array}$ & $\begin{array}{c}\text { Totalidad de } \\
\text { exportaciones } \\
\text { pesqueras peruanas } \\
\text { (millones de dólares). }\end{array}$ \\
\hline 2012 & 1083.65 & 99.79 & 2.98 & 288.91 (Alemania). & 3346.65 \\
2013 & 1049.11 & 38.8 & 1.40 & 264.09 (Estados Unidos) & 2764.29 \\
2014 & 939.52 & 157.04 & 5.39 & 268.30 (Estados Unidos) & 2912.21 \\
2015 & 1014.79 & 93.12 & 3.94 & 253.88 (Estados Unidos) & 2365.98 \\
2016 & 794.16 & 50.98 & 2.3 & 243.31 (Estados Unidos) & 2162.56 \\
2017 & 1323.11 & 88.06 & 3.1 & 268.11 (Estados Unidos) & 2829.02 \\
2018 & 1462.81 & 125.35 & 3.8 & 268.42 (Estados Unidos). & 3258.36 \\
2019 & 1480.526 & 241.39 & 6.91 & 260.48 (España) & 3495.63 \\
$202 *$ & 501.48 & 19.63 & 1.53 & 123.23 (Estados Unidos) & 1280.55
\end{tabular}

Fuente: Elaboración propia en base a datos de Sociedad Nacional de Pesquería (2012-2020).

\section{La peruanidad marítima. Legislación peruana sobre la jurisdicción marítima y en asuntos pesqueros.}

La República del Perú, casi desde su mismo surgimiento como Estado-Nación, pero con mayor énfasis desde el siglo XX, realizó distintos intentos para garantizar el control de los recursos existentes en el denominado Mar de Grau.

Perú fue de los primeros países en proclamar la necesidad de ampliar el ámbito de control y jurisdicción estatal sobre el océano, desde las 3 millas originalmente concebidas, hasta las 200 millas náuticas. Esta posición, en palabras de Morzone (1982) se sustentó a través de declaraciones oficiales en 1947, refrendadas en posiciones conjuntas con Chile y Ecuador como la Declaración de Santiago de 1952, la Conferencia de Lima en 1954, las Conferencias Interamericanas de Caracas, del mismo año, en Ciudad Trujillo en 1956, la Conferencia de Quito en 1955 y la Conferencia de Ginebra, en 1958. Esto llevó a disputas con Estados Unidos, que insistía en diversos foros internacionales con mantener la delimitación de las 3 millas, para ampliarlas hasta sólo 12 millas náuticas (Morzone, 1982: 209-211).

El Perú invocaba diversos principios jurídicos, geopolíticos, biológicos y económicos, como el derecho compensatorio, el cual implica que la extensión de la jurisdicción marítima compensaría la aridez y hostilidad climática del cinturón costero peruano, para el aprovechamiento de las riquezas ictícolas marinas. Al ser estos recursos de vital importancia para Perú, al menos hasta la proliferación de la minería a fines del siglo XX, se invocaban, como principios fundamentales, la autodefensa, protección y preservación de la Nación en relación a lo marítimo.

Finalmente, estos principios de las 200 millas náuticas se vieron reflejados en la legislación internacional a través de la Convención de las Naciones Unidas sobre el Derecho del Mar, firmada en Montego Bay, Jamaica, en 1982 y puesta en vigor en 1994. Desde entonces, esa distancia se fijó como límite de las Zonas Económicas Exclusivas de los Estados ribereños.

La tesis de la importancia de los factores geopolíticos, biológicos y económicos se reafirma en el último Libro Blanco de la Defensa Nacional (2006), en el cual se afirma el rol de los Andes y la Corriente de Humboldt para constituir al mar peruano como uno de los más ricos del mundo, constituyéndose en fuente de alimentación y de desarrollo 
industrial, destacando el rol del país como marítimo, andino, amazónico, bioceánico y con presencia en la Antártida y su posición como "nudo natural de comunicaciones terrestres, ferroviarias, marítimas y aéreas, facilitando el tráfico comercial y turístico recíproco en toda la región, constituyéndose en un pivote y centro estratégico para las comunicaciones terrestres, ferroviarias, fluviales, marítimas y aéreas de esta parte de América (Libro Blanco de la Defensa Nacional, 2006: 49).

En cuanto a la legislación pesquera peruana, la Ley General de Pesca de 1992, aprobada mediante el Decreto Ley Número 25977 fija, en el artículo 2, que "los recursos hidrobiológicos, por su condición de bienes patrimoniales de la Nación, son administrados por el Estado debiendo este participar de las rentas y beneficios producidos por su explotación". En el artículo 9 se expone que corresponde al Ministerio de Pesquería (posteriormente absorbido por el Ministerio de Producción) la creación de Planes de Ordenamiento o Reglamentos de Ordenamiento Pesqueros, los cuales deben conciliar el principio de sostenibilidad de los recursos pesqueros o conservación en el largo plazo, con la obtención de los mayores beneficios económicos y sociales, debiendo "considerar, según sea el caso, regímenes de acceso, captura total permisible, magnitud del esfuerzo de pesca, períodos de veda, temporadas de pesca, tallas mínimas de captura, zonas prohibidas o de reserva, artes, aparejos, métodos y sistemas de pesca, así como las necesarias acciones de monitoreo, control y vigilancia" (Decreto Ley Número 25977, 1999).

En el marco de estas regulaciones, el calamar gigante es uno de los siete productos marítimos que poseen un Reglamento de Ordenamiento Pesquero propio, dictado por el Ministerio de Producción, que se apoya en los informes del Instituto del Mar de Perú (IMARPE) sobre las capturas de recursos marítimos, el tamaño de las mismas y las condiciones biológicas y ambientales generales, para la fijación de las cuotas de captura anuales. En el caso de la pota, IMARPE realiza informes desde 1999.

El primer Reglamento de Ordenamiento Pesquero se dictó mediante Decreto Supremo en 2001, habilitando la entrada de buques extranjeros, con permisos de pesca y licencias de procesamiento a bordo otorgadas por concurso público de oferta de precios.

En el 2011, ese Reglamento fue sustituido por otro, dictado por el Ministerio de Producción (PRODUCE). Este último prioriza las embarcaciones nacionales, solicitándoles una autorización de incremento de flota y un permiso de pesca. En cambio, las embarcaciones extranjeras sólo están autorizadas a pescar, previa solicitud del permiso de pesca y la licencia de procesamiento a bordo, las cuales se asignan mediante concursos públicos de oferta de precios. El artículo 3, inciso 2, postula que sólo se permitirán las actividades de pesqueros extranjeros "Siempre que exista un excedente de la captura permisible no aprovechada por la flota nacional, y que no genere un impacto negativo a nivel social, económico y comercial sobre la industria nacional dedicada al procesamiento y exportación del recurso Calamar Gigante o Pota, derivado del análisis bio-económico y social" (PRODUCE, 2011, s/p). En cambio, las embarcaciones artesanales no precisan permisos de incremento de flota, solo el permiso de pesca y cumplimiento de la legislación sanitaria existente.

Desde el año 2012, las capturas de calamar gigante están limitadas a barcos artesanales de patente nacional, debido a la no renovación del régimen provisional para la extracción de pota por parte de pesqueros extranjeros, en 2010, que vencía en diciembre del 2011. Este régimen les permitía pescar, procesas y exportar directamente a sus países de origen, a más de 20 millas náuticas de distancia de la costa, hasta el 2011, en que se amplió a 80 millas (Csirke et al., 2018). 
Los estudios de Csirke et al., (2018) muestran que los mayores rendimientos de la pesca industrial fueron dentro de las 200 millas náuticas bajo jurisdicción peruana, entre los paralelos $4^{\circ}, 9^{\circ}$ Sur y hacia el centro y sur, durante la década de los noventa.

La pesca artesanal adquirió un crecimiento exponencial de las capturas desde inicios de la década del 2000, desde las 56 mil toneladas en 1999 a 533 mil en 2008 y de 556156 toneladas en 2014, en un contexto de progresiva desaparición de la pesca industrial de capitales extranjeros.

El IMARPE estableció diversas cuotas de captura anuales permitidas, dependiendo de las oscilaciones ambientales del mar peruano y las capturas reportadas. En 2019, se fijó como tope la captura de 450 mil toneladas de calamar. En vista de las circunstancias ambientales y que la población de pota no está en riesgo, ese tope aumentó $560 \mathrm{mil}$ toneladas en diciembre de ese año (Ministerio de Producción, 2019), repitiéndose en la cuota de captura del 2020 (Ministerio de Producción, 2020).

La Figura 1 muestra las áreas de mayor pesca del calamar gigante de parte de la flota nacional y con licencias de pesca peruanas.

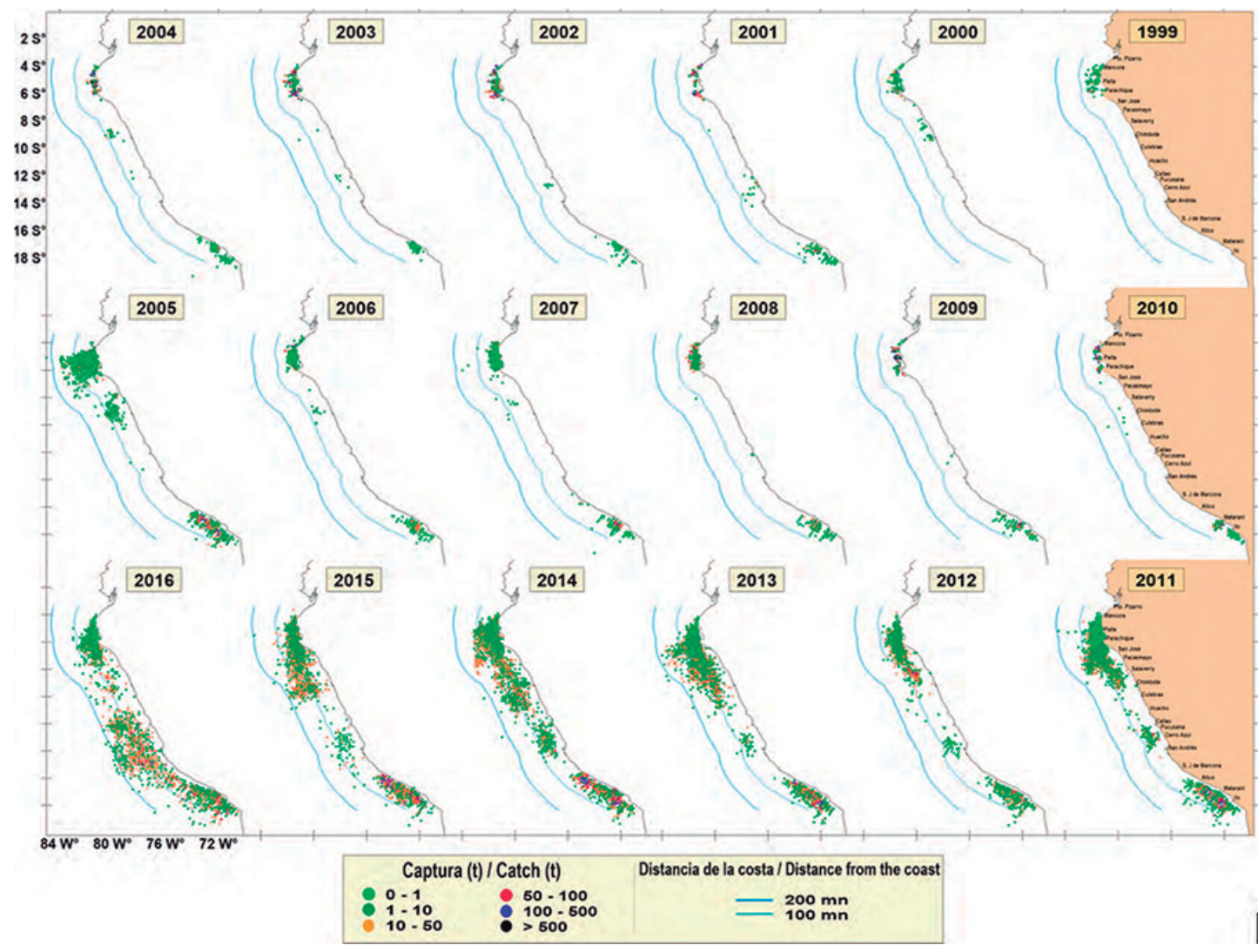

Figura 1. Distribución de las áreas de pesca artesanal del calamar gigante Dosydicus gigas (19992016). Fuente: Recuperado de Csirke et al., (2018).

Respecto a la pesca de flotas extranjeras en altamar, el Estado reconoce esta problemática, con la imposición en 2016 de una serie de disposiciones puntuales para regular el arribo de buques de banderas extranjeras. Estas facilitan el acceso a puertos o astilleros peruanos solo a barcos con pabellones de países que formen parte de Tratados y Acuerdos internacionales relacionados con la seguridad marítima, la conservación y preservación del medio marino y miembros o partes cooperantes no contratantes de Organismos Regionales de Ordenamiento Pesquero de los cuales el Perú es miembro, cuyos arribos deben ser comunicados al Ministerio de Producción. 
Los armadores de navíos que no cuenten con cuotas de captura o medidas que limiten el esfuerzo pesquero sobre los mismos y realicen transbordos o depósitos en tierra, serán multados a razón de 15 dólares por tonelada métrica descargada y los sospechados de actividades relacionados con la pesca INDNR, denunciados en organismos internacionales (Ministerio de Producción, 2016). Posteriormente, en ese mismo año, se agregó que los barcos que arribaran a puertos o astilleros peruanos, o quisieran utilizarlos, debían tener un sistema de seguimiento satelital, debiendo notificar al Ministerio de Producción en caso que quisieran hacer transbordos o descargas de productos en tierra (Ministerio de Producción, 2016a).

El Estado, a su vez, manifiesta una política represiva, de captura, confiscación de mercaderías y multas a barcos acusados de o encontrados en acciones de pesca INDNR en aguas peruanas. Para esto, se realizaron inversiones en estaciones de vigilancia y sistemas aéreos no tripulados, como la instalada en la localidad de Tumbes, con una inversión de 2,8 millones de soles. Desde enero a agosto del 2017, según el diario Gestión, se capturaron 64 embarcaciones que realizaban pesca INDNR, de las cuales 18 eran de China y Ecuador (¿A cuánto ascienden las multas de las embarcaciones capturadas por pesca ilegal?, 30 de agosto de 2017).

Esta peruanidad marítima también tuvo su correlato en las acciones llevadas a cabo por la Marina de Guerra, que proclama su finalidad de salvaguardar, proteger los recursos naturales y reprimir las actividades ilícitas, en la vigilancia de los límites de la Zona Económica Exclusiva frente a las denuncias de flotas pesqueras que se encontraban pescando Dosydicus gigas en sus adyacencias. En un comunicado emitido a fines de septiembre del 2020, la Marina puntualizó en las labores de monitoreo y vigilancia realizadas mediante el Sistema de Información y Monitoreo de Tráfico Acuático, con el uso de estaciones costeras, la realización de patrullajes con unidades guardacostas, buques patrulleros como el Río Cañete y aeronaves de exploración B-200. De esta manera, concluyeron que las flotas extranjeras, cerca de 250 naves de bandera china (Barcos chinos están frente al mar peruano desde hace muchos años (VIDEO) (25 de septiembre de 2020)) se encontraban en un espacio que abarca el territorio entre las 230 hasta las 350 millas de distancia del puerto de Pisco, por lo cual están lejos de la jurisdicción peruana (Marina de Guerra del Perú, 2020). El contraalmirante Jorge Portocarrero, en declaraciones a medios peruanos, refería que las acciones de las flotas responden a comportamientos estacionales, sin acercarse más allá de las 230 millas de la costa, con una movilidad en un área entre las adyacencias de las islas Galápagos y la zona del norte de Chile, la cual se basa en la migración del calamar gigante para su captura (Diario Correo, 2020). La Figura 2 ilustra las ubicaciones de las flotas chinas en las adyacencias de la Zona Económica Exclusiva peruana en el año 2019.

Con políticas como las reseñadas, se puede ver una administración del extractivismo pesquero, con la fijación de licencias para barcos artesanales nacionales y el sistema de castigos a quienes interfieran con la forma de acumulación del Estado a través de estas prácticas. En el contexto de inserción periférica de América Latina en el mercado mundial, en este caso como proveedor de materias primas a China como primer destino, los Gobiernos de diferentes signos políticos se ven beneficiados en lo fiscal con las prácticas extractivistas, mediante regalías mineras o, en este caso, los dividendos de las licencias pesqueras. 


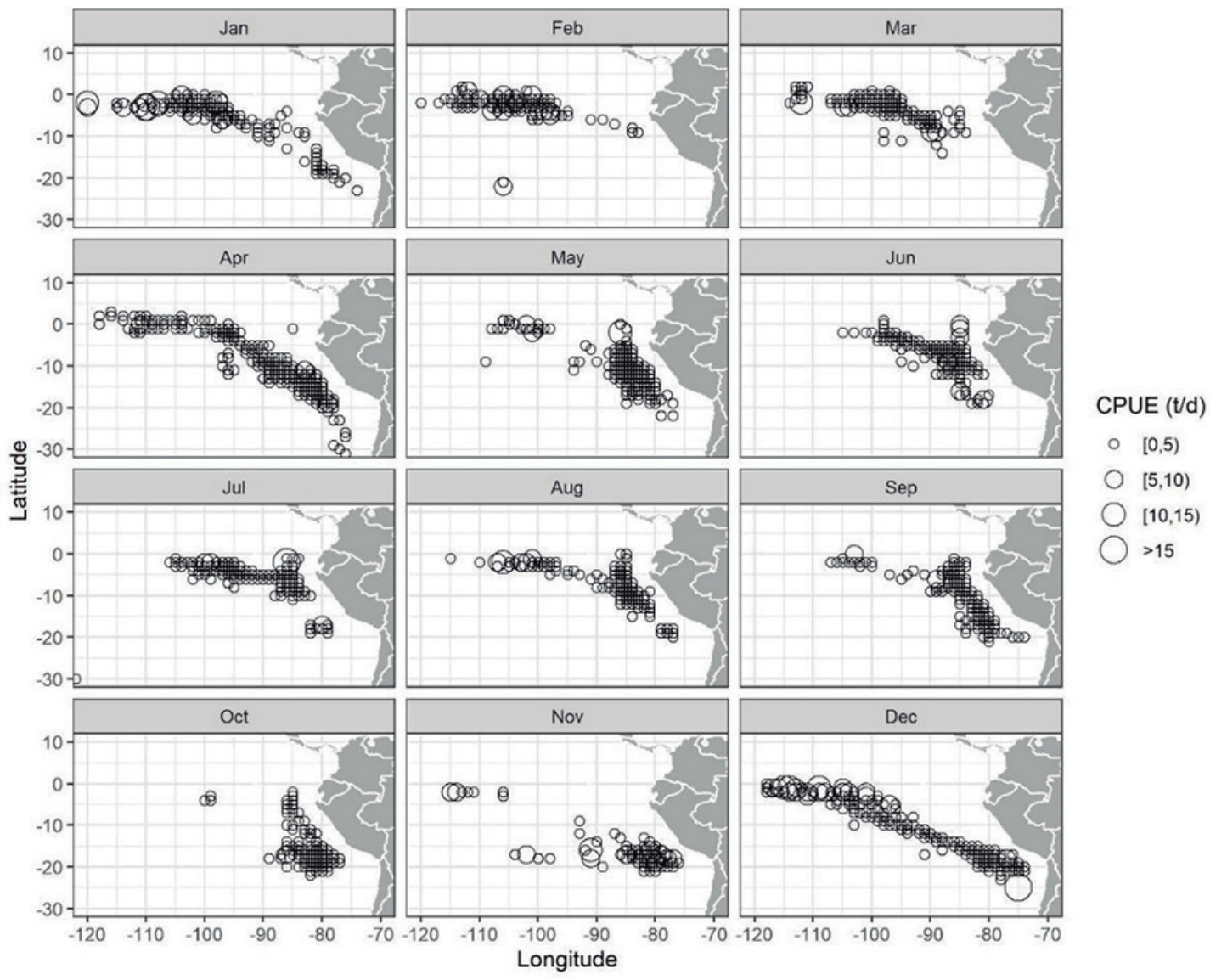

Figura 2. Distribución geográfica mensual de las flotas chinas en adyacencias de la Zona Económica Exclusiva peruana (2019). Fuente: Recuperado de Li et al., (2020).

Un mar de grises. La pesca china del calamar gigante.

La pesca legal china en el territorio del Perú. Algunos casos de fusiones y adquisiciones.

Desde los inicios de la década del 2000, China mantiene una presencia fuerte en América Latina. Según datos de la CEPAL (2015), el comercio entre estos dos bloques se multiplicó 22 veces entre los años 2000 y 2014 y China se ha constituido en el segundo socio de la región de América Latina en comercio e inversiones. En el caso peruano, el gigante asiático es el mayor socio comercial y uno de los mayores inversionistas en el país, sobre todo en el sector minero.

Estos procesos tienen como origen las reformas económicas llevadas a cabo por Deng Xiaoping desde 1978. Estas reformas liberalizadoras, de apertura y de modernización, llevaron a un enorme crecimiento industrial y de la urbanización, por ende, al incremento de la demanda china de productos de origen primario, desde materias primas para consumo personal o para la producción industrial (metales, petróleo, carbón, entre otros), lo que convirtió a China en el primer demandante mundial de commodities.

La relación con América Latina, proveedora tradicional de estos productos, se volvió estratégica para Beijing, condensándose en lo que Slipak (2015) bautizó como Consenso de las Commodities. La inserción china en la economía de América Latina, si bien tiene como horizonte la extracción y apropiación de diversos recursos naturales necesarios para sustentar el crecimiento de su producción y consumo interno, tiene diversas características a resaltar. 
Merino y Rang (2016) sostienen que, en el escenario de multipolaridad relativa, el avance chino como polo de poder mundial se apoya en la adquisición de empresas en el extranjero e inversiones en áreas críticas como energía y alimentación, la internacionalización no exenta de riesgos del yuan o renminbí, y las políticas de avance en los sectores de alta tecnología y servicios intensivos en alta complejidad (Merino y Rang, 2016: 38). Los flujos de IED tuvieron un crecimiento exponencial durante la década del 2000, coronada en el ciclo del auge de los precios de las materias primas entre 2007 y 2012, más allá de la caída en la magnitud de las inversiones por la creciente importancia de la Iniciativa Una Franja, Una Ruta y la guerra comercial con Estados Unidos, estas prácticas se mantienen en una menor escala.

CEPAL (Salazar-Xirinachs et al., 2019) destaca que China se centró en la adquisición y fusión con empresas de industrias extractivas, de agroindustria, generación de energía, servicios básicos (electricidad, gas y agua) e infraestructura. Esto facilita el acceso de Beijing a capacidades tecnológicas, posiciones de mercado, generación de energía, recursos naturales o infraestructura, lo cual posee una importancia considerable en el marco de las estrategias globales de liderazgo económico y tecnológico.

Para Slipak (2015), estas adquisiciones podrían generar efectos negativos en las economías de los países, no sólo porque los capitales chinos concentrarían el control de la oferta de los productos básicos, lo que conllevaría al control de los precios de los mismos, sino que impediría, o dificultaría, a los capitales nacionales, la apropiación de beneficios de estas actividades. La potenciación de las actividades extractivas ocurriría en desmedro de aquellas que implicaran mayor valor agregado, acentuándose la reprimarización de las economías y lo que Svampa (2013) denomina Consenso de las Commodities.

Si bien Perú exporta mayoritariamente minerales metálicos y sus manufacturas a China, se verifica un aumento de las exportaciones de productos "no tradicionales", como el calamar gigante, otros moluscos y algas, frutas, fibras de alpaca, maderas y productos químicos, con cifras que pasaron de 23 millones de dólares en 2000 a 361 millones en 2017 (Salazar-Xirinachs et al., 2018). El gigante asiático se volvió el principal socio comercial, a causa del TLC bilateral vigente desde 2010, y principal abastecedor de importaciones peruanas, que totalizaron 11455 millones de dólares en 2017, centradas en productos de alto y medio contenido tecnológico, como maquinarias, aparatos de telefonía, imagen, sonido, automóviles y motocicletas.

La inversión extranjera directa china totalizó, para 2017, el 5.6\% del total de las inversiones asiáticas en el país (1157 millones de dólares) en forma de adquisiciones, fusiones y asociaciones público privadas entre empresas estatales chinas y empresas peruanas. De esta forma, entre el 2009 y el 2017, se habrían generado 10600 empleos en el rubro de la pesca y acuicultura (Salazar-Xirinachs et al., 2018).

Uno de los ejemplos de empresas chinas en Perú, más no el único, es la China Fishery Group Ltd., (CFG) dependiente del holding chino Pacific Andes International Holding que, en base a datos de la Organización Internacional del Trabajo (Salazar Xirinachs et. al, 2018), habría generado el $12.3 \%$ del empleo total provisto por empresas chinas en 2017. Esta empresa opera en Perú desde las adquisiciones de Procesadora del Carmen, la adquisición del pesquero Isla Blanca S.A. y la empresa Alexandra S.A. en 2006, con una inversión que roza los 117 millones de dólares.

En el año 2007, CFG adquirió Pesquería Pocoma S.A.C., La Candelaria, Altoreal y Planta Chimbote por un total de 54 millones de dólares. Al año siguiente, invirtió 37.9 millones de dólares en las adquisiciones de Epesca Pisco, Pesquera Mistral, Pesquera Ofelia y Pesquera Islaya. En 2010, adquirió Dorbes Holding Corp. y Deep Sea Fishing por 113 millones de dólares. En el 2011, compraron Negocios Rafmar SAC y Consorcio Vollmatch por 26.2 millones de dólares. En 2013, los intentos de 
adquisición de Copeinca por un total de 809 millones de dólares (Salazar-Xirinachs et al., 2018), llevaron a complicaciones a la hora del pago por problemas administrativos y la menor producción pesquera peruana en los años subsiguientes.

De este modo, el holding Pacific Andes International adquirió siete plantas industriales y una flota de 20 embarcaciones con licencias peruanas y capacidad de extraer 9000 toneladas métricas de pescado. La solicitud de quiebra de la empresa China Fishery Group, en 2016, llevó a que se autorizara la venta de algunos de sus activos en 2018, aunque se mantienen las negociaciones para la concreción de la compra de Copeinca (Salazar-Xirinachs et al., 2018).

En un rubro análogo, la empresa estatal Cosco Shipping Ports adquirió parte de Terminales Portuarios Chancay, por 3000 millones de dólares, del 60\% de las operaciones, para ampliar el puerto y la capacidad de carga, tanto para barcos pesqueros como de carga y actividades relacionadas con la minería, como se refleja en la Tabla 2.

Tabla 2. Empresas pesqueras o portuarias chinas en el Perú. Adquisiciones y fusiones.

\begin{tabular}{cll}
\hline Empresas chinas & \multicolumn{1}{c}{ Filial en el Perú } & \multicolumn{1}{c}{ Adquisiciones y fusiones } \\
\hline Pacific Andes International Holding. & China Fishery Group Ltd. & 2006. Procesadora del Carmen. Pesquero Isla \\
& & Blanca. Empresa Alexandra S.A. \\
& 2007. Pesquería Pocoma S.A.C. \\
& La Candelaria. \\
& Altoreal. \\
& Planta Chimbote. \\
& 2008. Epesca Pisco. \\
& Pesquera Mistral. \\
& Pesquera Ofelia y Pesquera Islaya. \\
& 2010. Dorbes Holding Corp. Deep Sea Fishing. \\
& 2011. Negocios Rafmar SAC y Consorcio \\
Cosco Shipping Ports. & Vollmatch. \\
\hline
\end{tabular}

Fuente: Elaboración propia en base a datos de Salazar-Xirinachs et al., (2018).

\section{La pesca china y de otros países en altamar.}

Como se analizó en publicaciones previas (Ortega, Saavedra, Esquiroz: 2019; 2019a), los capitales chinos poseen una estrategia global de extracción de recursos pesqueros, patente no sólo en el Pacífico sudoriental, sino también en el Atlántico sudoccidental, en proximidades de la Zona Económica Exclusiva argentina y de aguas bajo control de facto del gobierno británico de ocupación de las islas Malvinas, con la presencia de un número variable de embarcaciones que pescan el calamar Illex argentinus. Estos procesos llevaron a intentos de negociación con el gobierno uruguayo para el establecimiento de un puerto hub o zona franca para depósito, abastecimiento y reparación de pesqueros en las cercanías de Montevideo (Ortega, Saavedra, Esquiroz; 2019).

Sala et al., (2018) estiman, en base a datos del 2014, que el 77\% de las flotas pesqueras de alta mar están bajo control de China, Taiwán, Japón, España, Corea del Sur e Indonesia, de los cuales los cinco primeros concentran el $64 \%$ de los ingresos por esta actividad, aunque cada país explota recursos en regiones distintas del mundo. Taiwán posee sus flotas más importantes que extraen recursos en el Pacífico noroeste, centro oeste y centro este. Los japoneses pescan sobre todo en el Pacífico centro occidental y centro oriental, en el Atlántico sur y en el Índico oriental. Corea del Sur tiene presencia en el Pacífico centro occidental, en el Atlántico Sur y sureste, además de aguas antárticas. España posee a sus flotas más importantes pescando en el Pacífico sudeste y sudoeste, en el Índico occidental, el Atlántico centro oriental (las costas africanas) y en el Atlántico Sur, en las aguas bajo control de facto del Gobierno de ocupación de Malvinas (Sala et al., 2018. Ortega, Saavedra, Esquiroz; 2019a). 
Al igual que en el Atlántico sudoccidental y en el Pacífico noroccidental, se constata la existencia de flotas de pesqueros chinos, taiwaneses y surcoreanos en el Pacífico sudoriental que oscilan entre los doscientos y cuatrocientos cincuenta barcos, que pescan, para Sala et al., (2018) sobre todo en aguas internacionales adyacentes a la Zona Económica Exclusiva peruana.

Según los datos del informe del think tank Overseas Development Institute (ODI) (Gutiérrez et al., 2020), que se basan en bases de datos privadas, algoritmos para inferir patrones de movimientos de barcos, Sistemas de Información Geográfica y Sistemas de Identificación Automática (AIS), existen 16996 pesqueros chinos en altamar, de los cuales 183 están observados como barcos que realizaron o realizan pesca INDNR. De esos 16996, 625 son buques pesqueros de calamares que usan el método de jigging, 163 lo hacen en las aguas del Pacífico Sur y 181 en el Atlántico sur (Gutiérrez et al., 2020: 18). Las diferencias en los guarismos responden a que el estudio de ODI toma en cuenta los barcos bajo propiedad de joint ventures (asociaciones entre empresas) o con banderas de otros países (Gutiérrez et al., 2020: 12).

En la década de los noventa, China se embarcó en un proceso de construcción de barcos para la "pesca en aguas distantes", que se mantuvo durante la década del 2000 (Sala et al., 2018).

Según documentos oficiales chinos presentados ante la Organización Regional de Ordenación Pesquera del Pacífico Sur (Li et al., 2018; 2019; 2020), la pesca china del calamar gigante en aguas adyacentes al Mar de Grau se inició en 2001, con 22 barcos. En 2017, 356 barcos capturaron 296.100 toneladas de calamares, 435 barcos pescaron 346.200 toneladas de calamares en 2018 y en 2019 fueron 503 buques los que capturaron 305700 toneladas de este recurso, respectivamente, previa merma durante los años 2015 y 2016, con un piso de 223.300 toneladas en ese año.

China confirmó la existencia de capturas desde la milla 201 hasta la 500, con casos de pesca a 900 millas de la costa (Csirke et al., 2018). La presencia de estos barcos es estacional, con mayor presencia en los meses de octubre a enero en el sur de Perú, en el período principal de desove del calamar y hacia el norte, en zonas cercanas a las aguas ecuatorianas en los meses de invierno ( $\mathrm{Li}$ et al., 2019).

Gutiérrez et al., (2020) postulan que la propiedad de los 6122 barcos que, según sus fuentes, conforman la flota de altamar china está desigualmente distribuida. Solo ocho compañías controlan más de cincuenta buques, mientras que el resto está bajo del dominio de 2228 empresas, las cuales son, en su mayoría, pequeñas y medianas. Esto se puede atribuir a un esquema de tercerización de las actividades, en pos de la reducción de riesgos, costos operativos, logísticos y fiscales de parte de las compañías más importantes. Esta situación es pasible de generar irregularidades y denuncias como las que se detallarán más adelante, que pueden ser o no fomentadas por parte de los grandes conglomerados transnacionales.

La empresa China National Fisheries Corporation (CNFC), subsidiaria de la estatal China Agricultural Development Group Co. que, según Gutiérrez, et al., (2020) es la que controla una buena parte de los pesqueros de la flota china de altamar, posee sedes en Ecuador, Venezuela y Surinam. En el primer país, la oficina de representación se estableció en 2005, para la pesca de calamar en aguas sudamericanas (CNFC, 2019).

En su presentación, la empresa aduce tener la flota pesquera más grande de China, que opera en el Atlántico, el Pacífico y el Índico, con 10 bases de procesamiento, almacenamiento y suministro de productos acuáticos dentro y fuera del país, además de cinco subsidiarias de capitales chinos, una en Senegal, otra en Mauritania y otra en Madagascar (CNFC China National Fisheries Corporation - Group Headquarters, 2020). 
La escala global de esta empresa se puede constatar en la multiplicidad de países en los cuales posee inversiones, uno de los cuales es España, donde tiene una oficina de ultramar en Las Palmas, en las islas Canarias, que funciona como centro comercial, logístico, de transferencia de pescado, gestión de proyectos y operaciones en África occidental y el oeste de Asia, de los que forman parte los 250 barcos de la flota de altura, 14 de transporte refrigerado con una capacidad total de 200000 toneladas anuales y dos de transporte de petróleo refinado (CNFC, 2019a), los cuales realizan servicios de recarga y suministro marino a embarcaciones que realizan operaciones pesqueras, con lo cual hay una admisión de hecho de la realización de transbordos en alta mar, práctica que puede dar lugar a menores declaraciones de capturas pesqueras. El concepto de Cóccaro (2002) de minería pesquera, y del diálogo entre lo terrestre y lo marítimo por las particularidades de la pesca, que precisa necesariamente de la instalación de infraestructura en tierra firme, es claro en este punto.

Gutiérrez et al., (2020) refiere que CNFC es la empresa que posee más barcos de pesca en altamar, con un total de 257 embarcaciones bajo su propiedad directa y con sede en Beijing, sumado a 128 en manos del Poly Group, 86 de propiedad de la Fujian Province Pingtan County Heng Li Fishery, 76 en la Dalian Chang Hai Yuan Yang Pelagic Fishery, 68 en manos de la Rongcheng Rong Yuan Fishery y 66 de propiedad de Yantai Marine Fisheries, su subsidiaria con sede en Shandong y a barcos de una serie de empresas pequeñas y medianas, también subsidiarias (Gutiérrez et al., 2020: 24). La mitad de la pesca china en aguas internacionales es reexportada a Europa, el norte de Asia y América, con las actividades de procesamiento centradas en el puerto de Zhoushan y, en menor medida, en Qingdao (Hornby, 2017).

\section{La rentabilidad de la pesca en altamar. El uso de los subsidios.}

La pesca en altamar, frecuentemente a miles de kilómetros de las bases propias de abastecimiento y con temporadas de varios meses, sino años en el océano, tiene múltiples costos logísticos a abordar, entre los cuales el más importante es el combustible. Para aliviar esta situación, se emplean diversas estrategias.

La primera radica en el uso de los puertos cercanos para el reabastecimiento, siempre que los pesqueros cumplan con las normativas vigentes en los Estados involucrados, caso contrario, los países que adhirieron al Acuerdo sobre Medidas del Estado Rector del Puerto prohíben el uso de sus instalaciones portuarias. Este problema puede ser solventado con el uso de banderas de terceros países para registrar a los barcos, algo también usado para aprovechar los menores impuestos y regulaciones ambientales y laborales, como el caso de Panamá o de varios países africanos.

La segunda acción implica el reabastecimiento de combustible y otros insumos mediante transbordos en aguas abiertas (Sala et. al, 2018) y la transferencia de las capturas a estos barcos de transporte o reefers, lo que permite a los pesqueros la no interrupción de sus actividades por meses e, incluso, años, al no necesitar puertos.

Documentos oficiales chinos, presentados a la Organización Regional de Gestión Pesquera del Pacífico Sur (Li et al., 2019) admiten la existencia de transbordos en dos buques con observadores a bordo, los nombrados Ningtai 66 y Ningtai 69, e intercambios con barcos como el Wei Shun, Wei Ning, He Shun y el Poseidón, todos de bandera liberiana y el Xin Hang, de bandera panameña.

La tercera práctica radica en la provisión de subsidios estatales, sobre todo al combustible. Sala et al., (2018) estiman que, para 2014, estas sumas totalizaban cerca de 4185 millones de dólares. En 2018, para Sumaila et al., (2019), los subsidios estatales a la pesca en alta mar, en todo el mundo, alcanzaron los 35400 millones de dólares, de los cuales 22200 millones se destinarían a la mejora de la capacidad de pesca, como la construcción, renovación y modernización de barcos, proyectos de desarrollo 
pesquero, construcción y renovación de puertos, marketing e inversiones en infraestructura y almacenamiento, exenciones impositivas y subsidios al combustible. Este último rubro alcanza los 7790 millones de dólares, a escala mundial. La ausencia de estos aportes, según Sala et al., (2018) haría que la actividad no fuera rentable en muchas regiones del mundo, como Perú, o aún menos rentables de lo que son con subsidios, como en el caso del Atlántico Sur (Sala et al., 2018: 5). De este modo, los Estados pesqueros más importantes subvencionan actividades económicas a todas luces deficitarias, en pos de garantizar el abastecimiento de productos marítimos, diezmados en sus regiones ribereñas por décadas de sobreexplotación y sobrepesca.

En el caso de China, el país con mayor proporción de capturas en alta mar (estimación de 1523 toneladas métricas para 2014), la política de subsidios al combustible diésel y de exenciones impositivas se empezó a implementar en 2006, de parte de los Ministerios de Agricultura y Finanzas (Mallory, 2016). Los subsidios habrían alcanzado, en el 2014, los 418 millones de dólares, solo superados por los otorgados por Japón y España (Sala et al., 2018). En 2018, los subsidios chinos, según las estimaciones de Sumaila et al., (2019) totalizaron los 7261 millones de dólares, entre aquellos otorgados por el Estado central y aquellos provistos por las provincias. Las diferencias de cifras se deben a variaciones técnicas, de metodología de extracción de datos y a las mismas dificultades de acceso a los datos oficiales chinos.

El 81\% de estos subsidios serían para mejorar las capacidades pesqueras, los cuales fueron duplicados desde el 2009. La pesca china en Perú en particular, y las actividades pesqueras en altamar a nivel general, según el análisis de Sala et al., (2018), solo serían redituables con la existencia de subsidios de los Gobiernos, los transbordos de combustible en alta mar y el uso de mano de obra barata o, lisa y llanamente, forzada o esclavizada. La ausencia de pagos de cánones que sí tendrían, en caso de pescar en Zonas Económicas Exclusivas de otros países, también constituye un factor que reduce los costos de la actividad.

Una de las mayores dificultades que implica la pesca en altamar radica en las formas de control de las actividades de las flotas. La Organización de las Naciones Unidas (ONU), en la Conferencia de Nueva York en 1994, sugirió la cooperación e intercambios de información entre los países ribereños y aquellos que pescaran en las adyacencias de las Zonas Económicas Exclusivas (ONU, 1995, s/p). De esta forma, se puede ver el concepto de Bouvet y Carut, referido a los alambrados invisibles.

Posteriormente, los mismos Organismos Regionales de Ordenación Pesquera (OROPs) conformados según estas recomendaciones, aplicaron progresivamente tecnologías satelitales de detección y de identificación de barcos, denominados Sistemas de Identificación Automática (AIS) y Sistema de Monitoreo de Embarcaciones (VMS) en los barcos que pescan en sus jurisdicciones. Los principales obstáculos radicarían en la menor declaración de información de los países miembros, la no colaboración entre países (al ser las OROPs de carácter voluntario en su conformación) y la metodología de apagado de los sistemas de detección para poder entrar en aguas jurisdiccionales de los países, pescar en ellos y retirarse luego de unas horas, cuando se vuelven a encender en aguas internacionales.

Estas prácticas entran en consonancia con el concepto mencionado de pesca INDNR. En el caso chino, que es el que se trata en el artículo debido a su inserción económica en América Latina y el tamaño de sus flotas, Gutiérrez et al., (2020) puntualiza que, de los 16966 buques pesqueros chinos, solamente 183 fueron denunciados por pesca INDNR (con una alta probabilidad de que existan más barcos no descubiertos realizando estas actividades), de los cuales las diez compañías tienen el $46 \%$ de estos barcos, y solo cuatro de estos son pesqueros de calamares o jiggers (Gutiérrez et al., 2020: 26-27). 
Existen múltiples denuncias de prácticas esclavistas y de trata de personas en buques chinos y de otros capitales (Transbordos en alta mar: la trampa del pescado "invisible", 15 de julio de 2018. Expertos arrojan halo de luz sobre la sombra de la pesca ilegal en el mundo, 24 de noviembre de 2019). Un factor clave podría ser el bajo costo de la mano de obra, tomando en cuenta las múltiples denuncias hechas por Organizaciones No Gubernamentales como la uruguaya Oceanosanos, que refieren a condiciones de explotación laboral, trata de personas e, incluso, esclavitud en pesqueros chinos, surcoreanos y taiwaneses que operan en el Atlántico Sur (Oceanosanos, 2018), en las cuales las víctimas son pescadores indonesios, birmanos, camboyanos y tailandeses, sobre todo. Cabe destacar que, en muchos casos, los pesqueros que extraen recursos en el Atlántico Sur y en el Pacífico Sur pertenecen a las mismas empresas o, incluso, son los mismos barcos y tripulaciones.

El informe del 2020 del Departamento de Estado del Gobierno de los Estados Unidos (DoS) (2020) califica a la flota de altamar taiwanesa como altamente vulnerable, donde los insuficientes protocolos de inspección impiden los esfuerzos para combatir el trabajo forzado, ya que las leyes laborales de Taiwán no protegen a los trabajadores pesqueros en altamar. Los pagos inferiores al salario mínimo, la no percepción de pagos o la coerción en base a deudas son prácticas comunes en los pesqueros taiwaneses. A pesar de esto, Estados Unidos sigue considerando al país asiático como Nivel 1 en regular la trata de personas, la mejor clasificación (DoS, 2020: 473, 476), en la cual Corea del Sur también se encuentra, a pesar la situación similar en cuanto a las flotas pesqueras, la escasez o nulidad de percepción de salarios, condiciones pésimas de trabajo, y donde los inspectores no suben a los barcos ni hablan con los trabajadores (DoS, 2020: 297-299)

China empezó a tener una política de mayor presión contra estas prácticas, más allá de no haber firmado los Acuerdos del Estado Rector del Puerto. Funcionarios chinos exponen que la pesca INDNR se debe a que existen compañías muy pequeñas y débiles, con manejos deficientes, poca seguridad y violaciones continuas a las regulaciones de altamar (Chun, 2018). Por esto, el XIII Plan Quinquenal plantea la búsqueda de la reducción gradual del subsidio al diésel (Sumaila et al., 2019, Ministerio de Agricultura y Asuntos Rurales, 2017, s/p), en paralelo a una política gubernamental de endurecimiento de las penalizaciones de barcos que cometan infracciones severas, el fomento al establecimiento de bases logísticas, la búsqueda de reducir el número de pesqueros a cerca de 3000, además de "mejorar de manera integral el nivel de ordenación estándar de la pesca de altura. Apoyar a las empresas para que crezcan más y fortalecerse mediante fusiones, reorganizaciones, adquisiciones, participaciones, etc., y cultivar un grupo de empresas pesqueras de alta mar modernas y líderes. Establecer y mejorar el sistema de "listas negras" para los empleados de la pesca en alta mar. Coordinar y promover las inspecciones de aplicación de la ley de pesca en alta mar, tomar medidas enérgicas contra las actividades de pesca INDNR y manejar de manera rápida y adecuada las violaciones de la pesca en alta mar relacionadas con el extranjero" (Ministerio de Agricultura y Asuntos Rurales, 2017, $\mathrm{s} / \mathrm{p})$.

Estas políticas se pueden deber a la presión de distintos medios internacionales, como Organizaciones No Gubernamentales y diversos Gobiernos. La lista negra de barcos por pesca ilegal, que implica la quita del subsidio al combustible que, como se mencionó previamente, es fundamental para la actividad en altamar. Esa política de tolerancia cero contra la pesca INDNR llevó a la sanción, hasta 2018, de 264 embarcaciones ilegales pertenecientes a 78 empresas pesqueras de aguas profundas, sumado a la rebaja de subsidios financieros estatales por 700 millones de yuanes, la descalificación de tres empresas pesqueras y la inclusión de 13 pesqueros en listas negras públicas de violaciones a las leyes (Ministerio de Agricultura y Asuntos Rurales, 2018, s/p), 
ya que autores (Chun, 2018) sostienen que estas listas existían desde el 2003 pero sin carácter público.

En enero de 2020, se empezó a contemplar un proyecto en China que endureciera los castigos hacia la pesca INDNR y aclara detalles en cuanto a su aplicación, con especial énfasis sobre la vigilancia. Se aumentarían las exigencias y mejorarían los sistemas para registrar los movimientos de los barcos, so pena de confiscación de los buques, la revocación de las licencias y la inclusión en las listas negras. En caso de que sean navíos extranjeros, tendrán prohibido el uso de los puertos chinos (Chun, 2020).

Una acción fundamental ocurrió el 1 de junio de 2020, con la declaración, de parte del Gobierno chino, de una moratoria unilateral en la pesca bajo su bandera en el Atlántico Sur y el Pacífico Sur, desde el 1 de septiembre al 30 de noviembre de cada año. En este último caso, el área de veda abarcaría desde el paralelo $5^{\circ}$ Norte, el $5^{\circ}$ Sur, el meridiano $95^{\circ}$ Oeste y el $110^{\circ}$ Oeste, a lo que se suma un fortalecimiento de la investigación científica, el monitoreo del calamar y la cooperación multisectorial (China comienza primera moratoria de pesca en alta mar, 2 de julio de 2020. Li. et al., 2020). Si bien son áreas relativamente pequeñas, configuran un avance en cuanto a las políticas chinas de control de la pesca en aguas que no son de su jurisdicción, pero donde las flotas de sus capitales pescan asiduamente.

La apropiación geoestratégica del combate a la pesca ilegal, por parte de los Estados Unidos. El rol de las Organizaciones No Gubernamentales.

En el mes de agosto de 2020, la Embajada estadounidense en Ecuador advirtió de la presencia de buques chinos en adyacencias de las islas Galápagos ("China aplicará una moratoria pesquera de tres meses frente a Galápagos", 5 de agosto de 2020). El Gobierno estadounidense, en el marco de la guerra mundial, híbrida y fragmentada, y en su búsqueda de apelar a una causa de fuerte impacto en la opinión pública de Occidente, recurrió a una guerra de comunicados, desde los cuales criticó las acciones de las flotas chinas.

Cabe considerar que la Administración Trump, en su Estrategia Nacional de Seguridad (Casa Blanca, 2017), marcó a China y a Rusia como poderes revisionistas que desafían el poder, la influencia e intereses estadounidenses y que erosionan tanto su seguridad como su prosperidad, en pos de formar un mundo consistente con su modelo autoritario, por lo tanto, antiético a los valores e intereses norteamericanos (Casa Blanca, 2017: 25). En línea con esto, la Estrategia Nacional de Defensa del Departamento de Defensa (DoD) (DoD, 2018) postula que China es un competidor estratégico que usa prácticas económicas predatorias para intimidar a sus vecinos mientras que militariza el mar de China meridional, en pos de reordenar la región del Indo Pacífico para su ventaja (DoD, 2018: 1-2).

En un documento centrado en la región del Indo-Pacífico, el Departamento de Estado (DoS) (2019) refiere a las amenazas de poderes revisionistas autoritarios sobre el orden libre y abierto que permitió la prosperidad de la región (DoS, 2019: 5). Los Estados Unidos consideran a la pesca ilegal, no declarada y no reglamentada como un crimen transnacional, al mismo nivel que el tráfico ilegal, el terrorismo, el extremismo violento y el ciberdelito, por lo cual realizan operativos conjuntos con Australia, Nueva Zelanda, Sri Lanka, Bangladesh y Maldivas (DoS, 2019: 11-12)

En el informe del Departamento de Estado sobre la trata de personas (2020), esta dependencia coloca a China como uno de los países peor calificados en esta temática, al ser un país que no realiza esfuerzos importantes en relación a esta problemática, sobre todo en el caso de la pesca, en la cual acusan al país de llevar a cabo medidas insuficientes que mantienen a los trabajadores bajo riesgo de ser sometidos a trabajos forzados, situación que ocurre en barcos chinos que operan en el Atlántico, Índico y 
Pacífico con pescadores africanos y del sudeste asiático, como birmanos, camboyanos y tailandeses (DoS, 2020: 153, 155-156).

Esta información tuvo como antecedentes las investigaciones de Organizaciones No Gubernamentales como la uruguaya Oceanosanos (2018), la cual tiene financiamiento de filántropos como Leonardo Di Caprio (entrevista realizada al ambientalista Milko Schwartzmann, octubre de 2019) y asociaciones sin fines de lucro como Oceana, que posee colaboración fundamental de Google, una empresa transnacional que autores como Merino (2018) ubican en la oposición a la Administración Trump, debido a sus acciones contrarias a la orden ejecutiva del Presidente de prohibir el ingreso al país a ciudadanos de siete países de Oriente Medio.

Google, al igual que Apple y Microsoft, es parte clave de las redes transnacionales que lideran el mercado mundial y gobiernan las Cadenas Globales de Valor, con una posición de vanguardia en la penetración del desarrollo tecnológico en el resto de los sectores de la economía. Por este motivo, consideran al mercado laboral, a la búsqueda de talentos para la innovación y el desarrollo de productos como una actividad de escala global, lo cual constituye una amenaza a la centralidad del Estado norteamericano proclamada por la Administración Trump (Merino, 2018: 31-32).

En agosto de 2020, el Secretario de Estado, Mike Pompeo, denunció la presencia de la flota china en Ecuador con un apoyo discursivo a los esfuerzos ecuatorianos para "garantizar que embarcaciones con la bandera china no participen en la pesca ilegal, no declarada y no reglamentada", sumado a la acusación de que "China subsidia la flota pesquera comercial más grande del mundo, que viola rutinariamente los derechos soberanos y jurisdicción de los estados costeros, pescando sin permiso" (EE. UU. respalda a Ecuador para vigilar flota pesquera china, 2 de agosto de 2020). Este apoyo declamado evidenciaría el fuerte alineamiento del Gobierno de Lenin Moreno con la Administración estadounidense.

En septiembre de 2020, la Embajada norteamericana en el Perú denunció, vía Twitter, la presencia de "una flota de más de 300 barcos de bandera de China con historial de cambiar nombres de barcos y desactivar rastreo por GPS está frente al Perú. La sobrepesca puede causar enormes daños ecológicos y económicos. Perú no puede permitirse semejante pérdida" (EE. UU alertó que 300 barcos pesqueros chinos navegaban en zona marítima peruana, 23 de septiembre de 2020). Estas declaraciones están en consonancia con las del mismo presidente Trump, en su discurso virtual para la Asamblea General de las Naciones Unidas, en septiembre de 2020 (Trump, 2020), donde señaló que China "tira millones y millones de toneladas de plástico y basura en los océanos, sobreexplota (overfishes) las aguas de otros países, destruye vastas extensiones de arrecifes de coral y emite más mercurio tóxico a la atmósfera que cualquier país en cualquier lugar del mundo".

La Guardia Costera estadounidense (USCG), en línea con estas declaraciones, sacó un documento en septiembre de 2020, en el cual expone una postura de colaboración contra la pesca INDNR, y se pone a la cabeza de la lucha contra esta actividad, que "erosiona tanto la seguridad regional como nacional, socava el orden marítimo legal, pone en peligro la disponibilidad y el acceso al alimento, y destruye las economías legales" (USCG, 2020: 2). De esta manera, se fomenta la aplicación de operativos de inteligencia, efectivos y con objetivos especificados, para contrarrestar los comportamientos irresponsables y predatorios de los Estados y expandiendo la cooperación entre pesquerías de los países.

El 23 de octubre de 2020, el Subsecretario de Estado para Asuntos del Hemisferio Occidental, Michael Kozak, mantuvo esta línea de acusar a China de sobrepesca y contravención de los acuerdos pesqueros, al alcanzar la flota del gigante asiático las adyacencias de la Zona Económica Exclusiva chilena. Según un video publicado en su 
cuenta de Twitter (2020), el mundo debe responsabilizar a Beijing por su insostenible pesca excesiva y la contaminación de los océanos, mientras que Estados Unidos y sus socios trabajan para garantizar la pesca legal y sostenible.

En contraposición a estos comunicados y declaraciones estadounidenses, el 28 de agosto de 2020, la Embajada China en Ecuador tildó a las críticas de injustificadas y sin ningún fundamento, añadiendo que "Los barcos pesqueros chinos que están operando en alta mar fuera de la ZEE de las islas Galápagos del Ecuador se adhieren estrictamente a las medidas de conservación y ordenación de la Organización Regional de Ordenación Pesquera del Pacífico Sur (SPRFMO) y la Comisión Interamericana del Atún Tropical (CIAT) (...) han publicado listados de barcos de pesca ilegal, no declarada y no reglamentada, y actualmente ningún barco pesquero chino figura en estos listados. China aplica las medidas más estrictas de vigilancia y control a los barcos de pesca pelágica, y exige a todos los barcos pesqueros que faenan en alta mar del Océano Pacífico sudoriental la instalación y utilización normal del Sistema de Seguimiento de Barcos (VMS, por sus siglas en inglés), realizando una vigilancia de su posición durante las 24 horas del día" (Embajada China en Ecuador, 2020, s/p) aunque admite que la señal del satélite generó que se retrasaran o perdieran temporalmente las señales de algunos barcos.

La Embajada China en Perú, el 22 de septiembre de 2020, sacó un comunicado por Twitter (2020), en el cual expone que "Como un país grande y responsable en la pesquería, China siempre concede suma importancia a la protección del ambiente y recursos de la oceanía (sic), y ejerce supervisiones y controles más estrictos a los barcos que están en operación ultramarina, al mismo tiempo de exigir consecutivamente a las empresas de pesca oceánica a respetar el Derecho Internacional y obedecer estrictamente las leyes y normas pertinentes del Perú, y limitarse a operar a alta mar. Esperamos que el público peruano no sea engañado por las informaciones falsas"

De esta forma, se puede ver como la situación de las flotas pesqueras chinas en Ecuador, Perú y Chile se orientó hacia una guerra de comunicados y declaraciones, en la cual ambos bandos buscaron la aprobación y la conformidad de la opinión pública mediante expresiones en redes sociales e Internet en general. Como se mencionó previamente, Perú tomó una postura de vigilancia y supervisión sobre las flotas en las aguas internacionales, sin que estas llegaran a acercarse lo suficiente para inferir alguna violación a las leyes marítimas peruanas mediante el apagado del sistema de detección satelital, lo que inferiría una entrada ilegal en la Zona Económica Exclusiva del país.

\section{Conclusiones}

Las prácticas extractivas pesqueras, sobre todo de capitales chinos, en adyacencias del Mar de Grau y dentro de la jurisdicción marítima peruana, representan una parte de la estrategia global tanto de pesqueras transnacionales como de una gran cantidad de pequeñas y medianas empresas que fungen de satélites, tercerizando pérdidas y gastos.

La estrategia china de inserción en América Latina está en consonancia con el plan "Una Franja, Una Ruta" de desarrollo de infraestructuras para abastecer de materias primas y recursos vitales para la economía del gigante asiático, de lo cual la pesca es un componente de no poca relevancia, a pesar de la escasa importancia brindada en los sectores académicos. Al ser este país el mayor exportador, el tercer importador a escala mundial y el que posee la mayor flota de altamar, las problemáticas de sustentabilidad, explotación e irregularidades presentes en un ámbito intensivo en mano de obra, de ganancias escasas o dependientes de los precios internacionales $\mathrm{y}$ de las condiciones ambientales se ven reflejadas en mayor medida, aunque estas 
prácticas son llevadas a cabo, a menor escala por el tamaño de sus flotas, por países como Taiwán, Corea del Sur, Japón, España y Gran Bretaña.

La pesca en altamar propiamente dicha no constituye un delito, debido a la inexistencia de regulaciones que la impidan, solo incurre en esta situación cuando se perpetran prácticas de pesca INDNR (Ilegal, No Declarada, No Reglamentada) o cuando realizan actividades sin autorización en Zonas Económicas Exclusivas de países ribereños con regulaciones más laxas o menor capacidad de reacción o de sanción. Aún en este caso, la proporción de pesqueros chinos que cometen este delito, según diversos analistas, es reducida en proporción al total.

No obstante esto, las prácticas pesqueras en aguas internacionales, al no estar reguladas o limitadas de la misma manera que si ocurrieran en jurisdicciones de Estados ribereños, son más pasibles de sobreexplotar los stocks de recursos marítimos, con enormes consecuencias para la biodiversidad, los ecosistemas oceánicos y para las mismas economías de los países, en caso de especies migratorias como los calamares, que se mueven de manera indistinta entre las Zonas Económicas Exclusivas y las aguas internacionales. Los calamares no reconocen las fronteras establecidas por la Humanidad.

La cobertura realizada por las Organizaciones No Gubernamentales, algunas de las cuales tienen un claro posicionamiento geoestratégico, es tomada por medios de comunicación y por Gobiernos geopolíticamente rivales de China con claros objetivos políticos. Estos últimos, como el Gobierno de los Estados Unidos, utilizan las críticas y denuncias para obtener ventaja en el marco de la actual guerra mundial, híbrida y fragmentada, en la cual se busca cualquier factor o elemento que pueda debilitar la capacidad productiva o militar de su rival, o simplemente generarle descrédito en la opinión pública. En este marco, los Estados Unidos buscan mantener su preeminencia en la región del Pacífico Sur frente al avance chino, mediante el uso de métodos no convencionales e incluso relacionados con las nuevas tecnologías de la información o la difusión por redes sociales.

Un capítulo del conflicto entre Estados Unidos y China ocurrió en el 2020 en aguas cercanas a Ecuador y al Perú. Si bien tuvieron características distintas por los recursos involucrados, por la cercanía a las jurisdicciones nacionales y por las diferentes respuestas estatales, que se centraron en la vigilancia de las flotas en pos de evitar su entrada a las aguas jurisdiccionales, esta situación responde a la lógica extractivista pesquera analizada previamente, en las cuales flotas de varios países, movilizados por la sobreexplotación de los recursos en sus aguas parten hacia distintos mares del mundo, detrás de recursos marítimos necesarios para los intereses de los capitales pesqueros. La misma vigilancia de las flotas mayoritariamente chinas configura una defensa del extractivismo pesquero controlado por el Estado, fuente de recursos fiscales.

En pos de la preservación de la biodiversidad del planeta, no solo por motivaciones económicas sino también ecosistémicas, es necesaria una regulación mucho más fuerte y un sistema legal que fije claramente las pautas de extracción de recursos marítimos, para evitar que las latitudes más alejadas de los océanos sean caldo de cultivo de prácticas criminales o que permitan la puesta en peligro, sino la desaparición de muchas especies en pos del lucro de los capitales concentrados. A su vez, el fortalecimiento de las Organizaciones de Regulación Pesqueras permitirá empoderar a las regiones ribereñas frente a los intentos de avance o de expoliación de cualquier potencia que quiera aprovechar sus posiciones de poder para obtener beneficios, pero terminar socializando las pérdidas, ya no con los países más inmediatamente perjudicados, sino con el planeta en su conjunto. 
Se considera que los Gobiernos del período analizado han fomentado las prácticas extractivistas en todas sus formas, mediante la provisión de licencias pesqueras y la defensa de la jurisdicción marítima de componentes que no aportan ingresos al Estado, debido a los beneficios fiscales que conlleva este modelo y a las características propias de la inserción de América Latina como región en el desarrollo del capitalismo globalizado. Como punto final, quedará pendiente para futuros trabajos la profundización sobre los aspectos políticos internos peruanos que llevaron a que las políticas extractivas pesqueras se hayan profundizado y tomado las características particulares actuales (octubre de 2020), en las que los pesqueros nacionales monopolizaron la extracción de recursos en las aguas jurisdiccionales del Perú.

\section{Referencias Bibliográficas}

¿A cuánto ascienden las multas de las embarcaciones capturadas por pesca ilegal? (30 de agosto de 2017). Diario Gestión. https://gestion.pe/economia/ascienden-multas-embarcacionescapturadas-pesca-ilegal-142618-noticia/

Barcos chinos están frente al mar peruano "desde hace muchos años" (VIDEO) (25 de septiembre de 2020). Correo Perú. https://diariocorreo.pe/peru/barcos-chinos-marinade-guerra-estan-frente-al-mar-peruano-desde-hace-muchos-anos-flota-pesquera-chinapisco-video-noticia/?ref $=\mathrm{dcr}$

Bouvet, Y (2018). “Recursos alimentarios y espacios marítimos: una geografía de la pesca en el mundo". En: Revista de Estudios Marítimos y Sociales, Año 11, Número 12, enero de 2018.

Bouvet, Y., Carut, C. (9-11 de noviembre de 2019). “El océano como bien común: las responsabilidades sobre las explotaciones pesqueras de Argentina y Francia". En: VII Congreso Nacional de Geografía de Universidades Públicas y XXI Jornadas de Geografía de la UNLP, La Plata, Argentina.

CEPAL (2015). América Latina y el Caribe y China. Hacia una nueva era de cooperación económica. Santiago de Chile. Naciones Unidas.

"China aplicará una moratoria pesquera de tres meses frente a Galápagos" (5 de agosto de 2020). El Mercurio. https://ww2.elmercurio.com.ec/2020/08/05/china-aplicara-unamoratoria-pesquera-de-tres-meses-frente-a-galapagos/

"China comienza primera moratoria de pesca en alta mar" (2 de julio de 2020). Xinhua Español. http://spanish.xinhuanet.com/2020-07/02/c_139181463.htm

Chun, Z. (4 de septiembre de 2018). China cracks down on illegal distant water fishing. China Dialogue Ocean. https://chinadialogueocean.net/4239-china-cracks-down-on-illegaldistant-water-fishing/

Chun, Z (21 de enero de 2020). China targets distant-water criminals with new fisheries law. China Dialogue Ocean. https://chinadialogueocean.net/12714-china-fisheries-law-distantwater-fishing/

CNFC (s/f). Envío logístico. https://cnfc.cnadc.com.cn/wlhy/index.jhtml

CNFC (2019). Oficina de representación en Ecuador. https://cnfc.cnadc.com.cn/zsznmz/7879. jhtml

CNFC (2019a). Las Office, España. https://cnfc.cnadc.com.cn/zszoz/7876.jhtml

CNFC China National Fisheries Corporation - Group Headquarters (2020). https://fis.com/ fis/companies/details.asp?l=s\&company_id=32635

Cóccaro J.M., Le Bail, J., Gómez O., Boetto A., (2000). “La minería pesquera ¿argentina?”. Publicado en: Actas del Segundo Encuentro Internacional Humboldt. Mar del Plata. http:// elistas.egrupos.net/lista/encuentrohumboldt/archivo/indice/504/msg/543/

Csirke J., Argüelles J., Alegre A., Ayón P., Bouchón M., Castillo G., Castillo R., Cisneros R., Guevara-Carrasco R., Lau L., Mariátegui L., Salazar C., Tafur R., Torrejón J., Yamashiro C., (2018). "Biología, estructura poblacional y pesquería de pota o calamari gigante (Dosidicus gigas) en el Perú". En: Boletín del Instituto del Mar de Perú. Volumen 33, Número 2. Julio-diciembre. 
Department of Defense (2018). Summary of the 2018 National Defense Strategy of The United States of America. Sharpening the American Military's Competitive Edge. https://dod.defense.gov/ Portals/1/Documents/pubs/2018-National-Defense-Strategy-Summary.pdf

Department of State (2019). A free and open Indo-Pacific. Advancing a Shared Vision. https://www. state.gov/wp-content/uploads/2019/11/Free-and-Open-Indo-Pacific-4Nov2019.pdf

Department of State (2020). Trafficking in persons report. 20th edition. Junio 2020. Departamento de Estado, Estados Unidos de América. https://www.state.gov/wp-content/ uploads/2020/06/2020-TIP-Report-Complete-062420-FINAL.pdf

"EE. UU. alertó que 300 barcos pesqueros chinos navegaban en zona marítima peruana" (23 de septiembre de 2020). Deutsche Welle. https://www.dw.com/es/ee-uualert\%C3\%B3-que-300-barcos-pesqueros-chinos-navegaban-en-zona-mar\%C3\%ADtimaperuana/a-55031899

“EE.UU. respalda a Ecuador para vigilar flota pesquera china". (2 de agosto de 2020). https://www.dw.com/es/eeuu-respalda-a-ecuador-para-vigilar-flota-pesquerachina/a-54409649

Embajada de China en Ecuador (2020). "Comunicado de la Embajada de China en Ecuador sobre los comentarios injustificados y repetidos del Secretario de Estado de Estados Unidos Mike Pompeo de los buques pesqueros chinos (2020-08-28)". http://ec.chinaembassy.org/esp/sgxw/t1810331.htm

Embajada de China en Perú [@ChinaEmbPeru] (22 de septiembre de 2020). “Comunicado de la Embajada de China en Perú". [Tweet]. Twitter. Recuperado de: https://twitter.com/ ChinaEmbPeru/status/1308561867963535360/photo/1

"Expertos arrojan halo de luz sobre la sombra de la pesca ilegal en el mundo" (24 de noviembre de 2019). Diario Gestión. https://gestion.pe/economia/expertos-arrojan-halo-de-luzsobre-la-sombra-de-la-pesca-ilegal-en-el-mundo-noticia/?ref=gesr

Gobierno de Perú (1999). Ley General de Pesca. Decreto Ley N.o 25977. https://www.peru.gob.pe/ docs/PLANES/14303/PLAN_14303_2015_LEY_25977_LEY_GENERAL_DE_PESCA.PDF

Gobierno de Perú (2006). Libro Blanco de la Defensa Nacional. https://cdn.www.gob.pe/uploads/ document/file/397073/Libro_blanco.pdf

Gudynas, E. (2015). Extractivismos. Ecología, economía y política de un modo de entender el desarrollo y la Naturaleza. Cochabamba; CEDIB y CLAES / 2a ed. Lima: RedGE, PDTG y CLAES.

Gutiérrez M., Daniels A., Jobbins G., Gutiérrez Almazor G., Montenegro C., (2020). Chinás distant-water fishing fleet: scale, impact and governance. Junio 2020, ODI, Londres.

Hornby L., (27 de marzo de 2017). "A bigger catch: China's fishing fleet hunts new ocean targets". Financial Times. https://www.ft.com/content/e7bd4094-ff34-11e6-96f8-3700c5664d30

Kozak M. [@WHAsstSecty] (23 de octubre de 2020). “La enorme flota pesquera de la República Popular China sigue saqueando los mares de la costa de América del Sur y ahora está cerca de Chile. El mundo debe estar alerta y responsabilizar a China por su insostenible pesca excesiva y la contaminación de los océanos." [Tweet]. Twitter. https:// twitter.com/WHAAsstSecty/status/1319629647949094918/video/1

Li G., Liu B., Xu L., Chen X., (2018). "Annual Report of China to the 2018 SRPFMO Science Committee Part II: the Squid Jigging Fishery". https://www.sprfmo.int/meetings/ scientific-committee/6th-sc-2018/

Li G., Liu B., Xu L., Chen X., (2019). "Annual Report of China to the 2019 SRPFMO Science Committee Part II: the Squid Jigging Fishery". https://www.sprfmo.int/meetings/ scientific-committee/7th-sc-2019/

LiG., Zou X., Xu L., (2020). “Annual Report of China to the 2020 SPRFMO Scientific Committee. Part II: The Squid Jigging Fishery". https://www.sprfmo.int/meetings/scientificcommittee/8th-sc-2020/

Mallory T.G, (2016). "Fisheries subsidies in China: Quantitative and qualitative assessment of policy coherence and effectiveness". En: Marine Policy. Número 68. 
Marina de Guerra del Perú (22 de septiembre de 2020). Comunicado Número 8 de la Marinade Guerra del Perú. La Perla. Recuperado de: https://www.marina.mil.pe/es/comunicacion/ comunicado/marina-de-guerra-del-peru-56/

Merino G., Rang C., (coordinadores) (2016). ¿Nueva Guerra Fría o guerra mundial fragmentada?: El resurgir de Rusia, el avance de China, los nuevos bloques emergentes y el desafío a las fuerzas unipolares de Occidente. Posadas; Editorial de la Universidad Nacional de Misiones.

Merino G., (2018). “Los tratados comerciales y las luchas globales en la era Trump”. En: Realidad Económica. N 313, año 47.

Ministerio de Agricultura y Asuntos Rurales de China (21 de diciembre de 2017). “Decimotercer plan quinquenal nacional de desarrollo de la pesca en alta mar". http://www.moa.gov. cn/gk/ghjh_1/201712/t20171227_6128624.htm

Ministerio de Agricultura y Asuntos Rurales de China (20 de marzo de 2018). “Anuncio del Ministerio de Agricultura y Asuntos Rurales en la investigación de presuntas violaciones de las regulaciones de algunas empresas pesqueras de altamar y buques pesqueros". http://www.moa.gov.cn/gk/ghjh_1/201712/t20171227_6128624.htm

Ministerio de Producción (2011). “Reglamento del Ordenamiento Pesquero del Calamar Gigante o Pota". http://www2.produce.gob.pe/dispositivos/publicaciones/2011/octubre/ ds014-2011-produce.pdf

Ministerio de Producción (2016). “Decreto Supremo No016-2016". https:// busquedas.elperuano. pe/normaslegales/establecen-medidas-para-autorizar-operaciones-en-puertos-y-adecreto-supremo-n-016-2016-produce-1408438-6/

Ministerio de Producción (2016a). “Decreto Supremo No025-2016". https://busquedas. elperuano.pe/normaslegales/decreto-supremo-que-modifica-los-articulos-3-y-4-deldecreto-decreto-supremo-n-026-2016-produce-1466666-7/

Ministerio de Producción (2019). “Resolución Ministerial No 533-2019”. https://cdn.www.gob. pe/uploads/document/file/442215/-270832840983727977920191216-22647-tua72b.pdf

Ministerio de Producción (2020). “Resolución Ministerial No 100-2020". https://cdn.www.gob. pe/uploads/document/file/538808/RM_N\%C2\%BA_100-2020-PRODUCE.pdf

Morzone L., (1982). Soberanía territorial argentina. Buenos Aires; Ediciones De Palma

Oceanosanos (2018). Pesca Ilegal, No Declarada y No Reglamentada en el Atlántico Sur. Trabajo esclavo, trata y muerte en el Puerto de Montevideo. www.oceanosanos.org/Informes

Organización de las Naciones Unidas (1995). Acuerdo sobre la aplicación de las disposiciones de la Convención de las Naciones Unidas sobre el Derecho del Mar de 10 de diciembre de 1982 relativas a la conservación y ordenación de las poblaciones de peces transzonales y las poblaciones de peces altamente migratorios. Sexto período de sesiones, Nueva York, 24 de julio a 4 de agosto de 1995.

Organización de las Naciones Unidas para la Alimentación y la Agricultura (2020). Fishery and aquaculture statistics 2018. http://www.fao.org/fishery/statistics/programme/ publications/all/es

Organización de las Naciones Unidas para la Alimentación y la Agricultura (FAO, 2020a). "Pesca ilegal, no declarada y no reglamentada (pesca INDNR)". http://www.fao.org/iuufishing/background/what-is-iuu-fishing/es/

Organización de las Naciones Unidas para la Alimentación y la Agricultura (s/f). FAO Major Fishing Areas. Pacific Southeast (Major Fishing Area 87). http://www.fao.org/fishery/area/ Area87/en

Ortega, F. Saavedra, D. Esquiroz, F (9-11 de noviembre de 2019). "Entre calamares y medianoche. El extractivismo pesquero chino en el Atlántico Sur". Presentado en: VII Congreso Nacional de Geografía de Universidades Públicas y XXI Jornadas de Geografía de la UNLP. Universidad Nacional de La Plata, La Plata, Argentina.

Ortega, F. Saavedra, D. Esquiroz, F (28 de noviembre de 2019). “Licencia para depredar: el extractivismo pesquero en Malvinas". Presentado en: II Jornadas sobre la Cuestión Malvinas. Universidad Nacional de La Plata, La Plata, Argentina. 
Paredes C., (2012). Eficiencia y equidad en la pesca peruana: La reforma y los derechos de pesca. Instituto del Perú, Universidad de San Martín de Porres. Noviembre del 2012.

Sala E., Mayorga J., Costello C., Kroodsma D., Palomares M. L.D., Pauly D., Sumaila U. R., Zeller D., (2018). "The economics of fishing the high seas". En: Science Advances. Número 4. Junio de 2018.

Salazar-Xirinachs J.M., Dussel Peters E., Armony A.C., (editores) (2018). Efectos de China en la cantidad y calidad del empleo en América Latina. México, Perú, Chile y Brasil. Organización Internacional del Trabajo.

Slipak A., (2015). “China en América Latina: Del Consenso de los Commodities al Consenso de Beijing". En: Ensambles. Año 2, Número 3.

Sociedad Nacional de Pesquería (2012-2020). “Industria pesquera: Contribución a la economía peruana". https://www.snp.org.pe/relevancia-economica/

Sumaila U.R., Ebrahim N., Schuhbauer A., Skerritt D., Li Y., Kim H.S., Mallory T.G., Lam V. W.L., Pauly D., (2019). "Updated estimates and analysis of global fisheries subsidies”. En: Marine Policy. Número 109.

Svampa M., (2013). “Consenso de los commodities y lenguajes de valoración en América Latina". En: Nueva Sociedad. Número 244, Buenos Aires, marzo-abril 2013. https:// nuso.org/articulo/consenso-de-los-commodities-y-lenguajes-de-valoracion-en-americalatina/

"Transbordos en alta mar: la trampa del pescado "invisible"." (15 de julio de 2018). https:// gestion.pe/economia/transbordos-alta-mar-trampa-pescado-invisible-238435-noticia/

Trump, Donald [The White House] (22 de septiembre de 2020). "President Trump Addresses the 75th Session of the United Nations General Assembly". [Archivo de video]. Recuperado de: https://www.youtube.com/watch?time_continue=4\&v=MWFQ0sHnutk\&feature $=e m b$ title

United States Coast Guard (2020). Illegal, Unreported and Unregulated Fishing Strategic Outlook. Washington D.C., Septiembre de 2020. https://www.uscg.mil/Portals/0/Images/iuu/ IUU_Strategic_Outlook_2020_FINAL.pdf 